\title{
Tackling colorectal cancer as a public health issue: What can the gastroenterologist do?
}

\author{
Catherine Dubé MD MSc FRCPC
}

$\mathrm{C}^{\mathrm{d}}$ olorectal cancer (CRC) is an important public health issue. It is the second leading cause of cancer death among Canadians (9200 estimated deaths in 2012), the third most common cancer diagnosis overall $(23,300$ estimated new cases in 2012) and it will be responsible for $13.3 \%$ of all new cancer diagnoses in Canada this year (1). CRC lends itself particularly well to screening because it is a slowly progressive disease that is asymptomatic in its early stages, affecting a welldescribed target population and can be cured if treated early. Moreover, there is very good evidence supporting the effectiveness of screening for reducing $\mathrm{CRC}$ incidence as well as CRC-related mortality, yielding mortality reductions ranging between $12 \%$ and $43 \%$ depending on the screening modality and data analysis $(2,3)$. Organized CRC screening is also cost effective (4-6). In fact, of all cancer screening interventions, CRC screening is recognized as one of the most effective. Yet, screening rates remain low in Canada. The 2008 Canadian Community Health Survey revealed that only 32\% (range 16\% to 46\%) of Canadians 50 to 74 years of age reported having undergone either a fecal occult blood test in the past two years or a sigmoidoscopy/colonoscopy in the past five years for nonsymptomatic reasons (7).

In the current issue of the Canadian Journal of Gastroenterology, Wang et al (8) (pages 419-423) from Edmonton (Alberta) report on the CRC screening delay in average-risk individuals as well as those with a positive family history. Organized CRC screening has yet to be implemented in Alberta, such that CRC screening occurs in an opportunistic fashion (ie, either being initiated by patients or through recommendation from their treating physician[s]). There was a delay in the time to first screening of 14.4 years and 8.2 years in those with a significant family history of CRC and those at average risk, respectively. When questioned about the perceived risk of CRC, $56.2 \%$ and $42.7 \%$ of those with a family history and of those at average risk, respectively, rated their risk inappropriately, most of the time underestimating that risk. These findings are supported by a recent panCanadian survey of 4050 Canadians 45 to 74 years of age on their understanding and attitudes toward getting screened for CRC. In this survey, $92 \%$ of Canadians agreed that cancer screening was a medical test to detect cancer; however, 53\% mistakenly believed that initial screening should happen only after symptoms are noticed (9).

Multiple barriers can limit population participation, one of which, as identified by Wang et al, is the lack of patient awareness of their personal risk for CRC and the lack of initiation of screening by family doctors. However, there is also the need to move from an opportunistic model of screening to that of established programs that can monitor the participation in the target population and develop interventions to increase that participation. Ultimately, it is the achievement of a high level of participation that will impact CRC incidence and mortality. As a reference, the European Guidelines for
Quality Assurance in Colorectal Cancer Screening and Diagnosis (10) recommend to achieve a participation rate of at least $65 \%$ among the target population.

While public health and primary care should be devoting efforts toward increasing awareness of and participation in screening, gastroenterologists and endoscopists are faced with other issues such as maintaining the fine balance between timely access to care for patients with symptoms while ensuring that CRC screening can effectively take place. This becomes particularly challenging when gastroenterologists recommend that screening of the average-risk population be performed using colonoscopy because limitations in infrastructure and manpower make this approach to CRC screening practically incompatible with the goal of reaching participation rates of at least $65 \%$. Up until recently, this dilemma was a significant cause of limited access to screening: primary care physicians and gastroenterologists alike have little confidence in the traditional guaiac-based fecal occult blood test, leading to a preference for screening colonoscopy. However, with the availability of the more sensitive fecal immunochemical test (FIT), this tension between screening and acute care can hopefully be resolved because FIT represents a reasonable alternative to colonoscopy for screening of the average-risk population $(4,5,11-13)$. Depending on the cut-off for FIT positivity and the number of samples taken, the number needed to colonoscope to diagnose a CRC from a population of FIT-positive individuals varies between 9.8 and $18.5(11,14)$. This is in contrast to the number needed to colonoscope from a population of average-risk individuals, which ranges between 191 and 240 (11, personal communication: A Rostom, Forzani \& MacPhail Colon Cancer Screening Centre, Department of Gastroenterology, University of Calgary, Calgary, Alberta). This not only frees endoscopy space, but also reduces the exposure of the screened population to the risks of complications from colonoscopy.

Gastroenterologists and endoscopists at large need to approach CRC as a public health problem, sharing the ultimate goal to reduce CRCrelated morbidity and mortality in the population through CRC screening. In this optic, they should support and recommend the screening modality that optimizes the balance between access (to optimize population participation) and ability to detect CRC. Freeing endoscopy space by restricting screening-related colonoscopies to individuals with abnormal FIT results, higher-risk individuals, and to those requiring adenoma and/or CRC surveillance, will significantly reduce the tension created by the competing demands between acute care and screening. Once access to colonoscopy can be assured, is it then possible for public health initiatives to successfully promote and facilitate CRC screening to formally institute organized screening without fear of creating backlogs for acute care gastroenterology. This, in turn, will finally enable us to effectively participate in reducing the burden of CRC in the population.

Division of Gastroenterology, Department of Medicine, University of Calgary, Calgary, Alberta

Correspondence: Dr Catherine Dubé, Division of Gastroenterology, Department of Medicine, University of Calgary, 3280 Hospital Drive

Northwest, Calgary, Alberta T2N 4N1. Telephone 403-592-5089, fax 403-592-5090, e-mail dubec@ucalgary.ca

Received and accepted for publication June 15, 2012 


\section{REFERENCES}

1. Canadian Cancer Society's Steering Committee on Cancer Statistics. Canadian Cancer Statistics 2012. Toronto: Canadian Cancer Society, 2012.

2. Hewitson P, Glasziou P, Watson E, Towler B, Irwig L. Cochrane systematic review of colorectal cancer screening using the fecal occult blood test (Hemoccult): An update. Am J Gastroenterol 2008;103:1541-9.

3. Atkin WS, Edwards R, Kralj-Hans I, et al. Once-only flexible sigmoidoscopy screening in prevention of colorectal cancer: A multicentre randomized controlled trial. Lancet 2010;375:1624-33.

4. Zauber AG, Lansdorp-Vogelaar I, Knudsen AB, Wilschut J, Van BM, Kuntz KM. Evaluating test strategies for colorectal cancer screening: A decision analysis for the U.S. Preventive Services Task Force. Ann Intern Med 2008;149:659-69.

5. Heitman SJ, Hilsden RJ, Au F, Dowden S, Manns BJ. Colorectal cancer screening for average-risk North Americans: An economic evaluation. PLoS Med 2010;7:e1000370.

6. Sharp L, Tilson L, Whyte S, et al. Cost-effectiveness of populationbased screening for colorectal cancer: A comparison of guaiac-based faecal occult blood testing, faecal immunochemical testing and flexible sigmoidoscopy. Br J Cancer 2012;106:805-16.

7. Canadian Community Health Survey, Ottawa: Statistics Canada, 2008.
8. Wang H, Gies N, Wong C, Sadowski D, Moysey B, Fedorak R. Patients undergoing colorectal cancer screening underestimate their cancer risk and delay presentation for screening. Can J Gastroenterol 2012;26:419-23.

9. Canadian Partnership Against Cancer, Canadians' Awareness and Attitudes towards Colorectal Cancer Screening, Jan 2012.

10. European Commission. European guidelines for quality assurance in colorectal cancer screening and diagnosis, - 1st edn. Segnan N, Patnick J, von Karsa L, eds. Luxembourg: Publications Office of the European Union, 2012.

11. Quintero E, Castells A, Bujanda L, Cubiella J, et al. Colonoscopy versus fecal immunochemical testing in colorectal-cancer screening. N Engl J Med 2012;366:697-706.

12. van Rossum LG, van Rijn AF, Laheij RJ, et al. Random comparison of guaiac and immunochemical fecal occult blood tests for colorectal cancer in a screening population. Gastroenterology 2008;135:82-90.

13. Hol L, van Leerdam ME, Van BM, et al. Screening for colorectal cancer: Randomised trial comparing guaiac-based and immunochemical faecal occult blood testing and flexible sigmoidoscopy. Gut 2010;59:62-8.

14. van Roon AHC, Wilschut JA, Hol L, et al. Diagnostic yield improves with collection of 2 samples in fecal immunochemical test screening without affecting attendance. Clin Gastroenterol Hepatol 2011;9:333-9. 


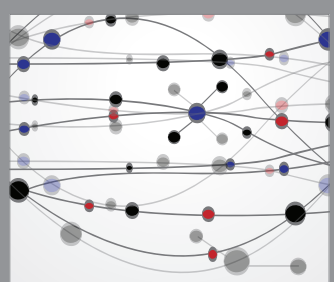

The Scientific World Journal
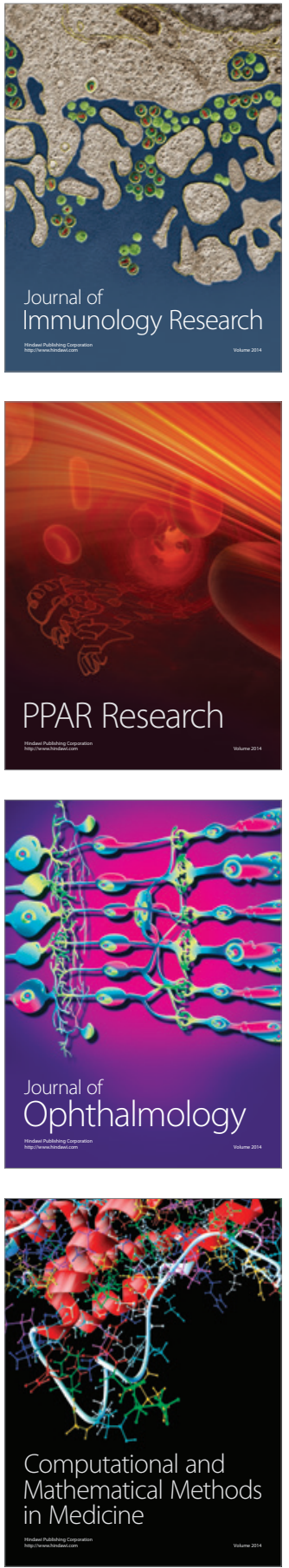

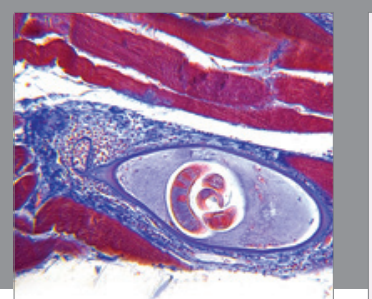

Gastroenterology Research and Practice

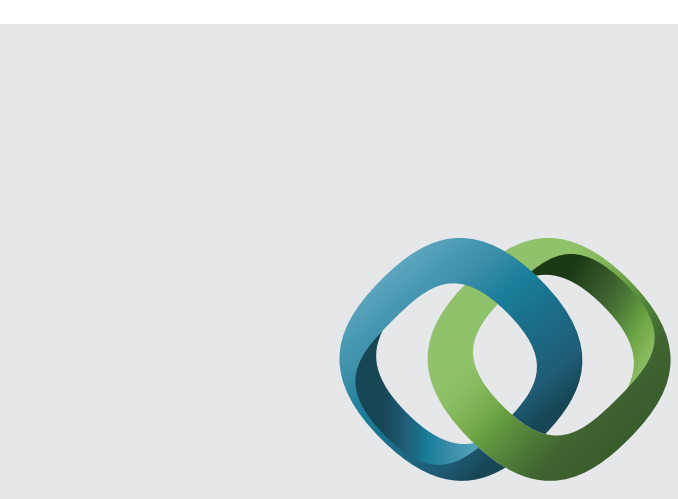

\section{Hindawi}

Submit your manuscripts at

http://www.hindawi.com
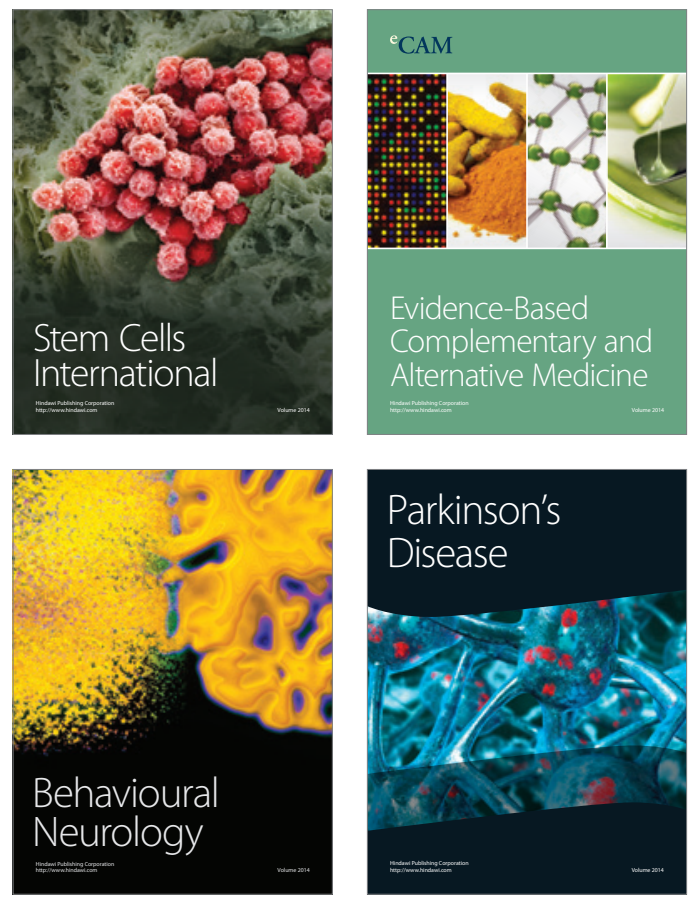
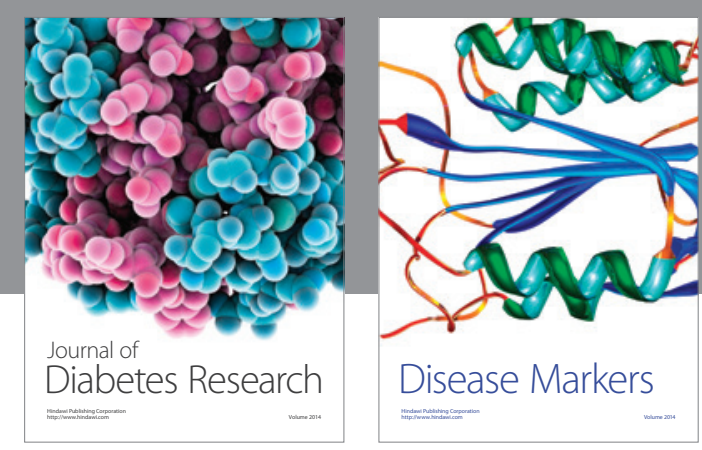

Disease Markers
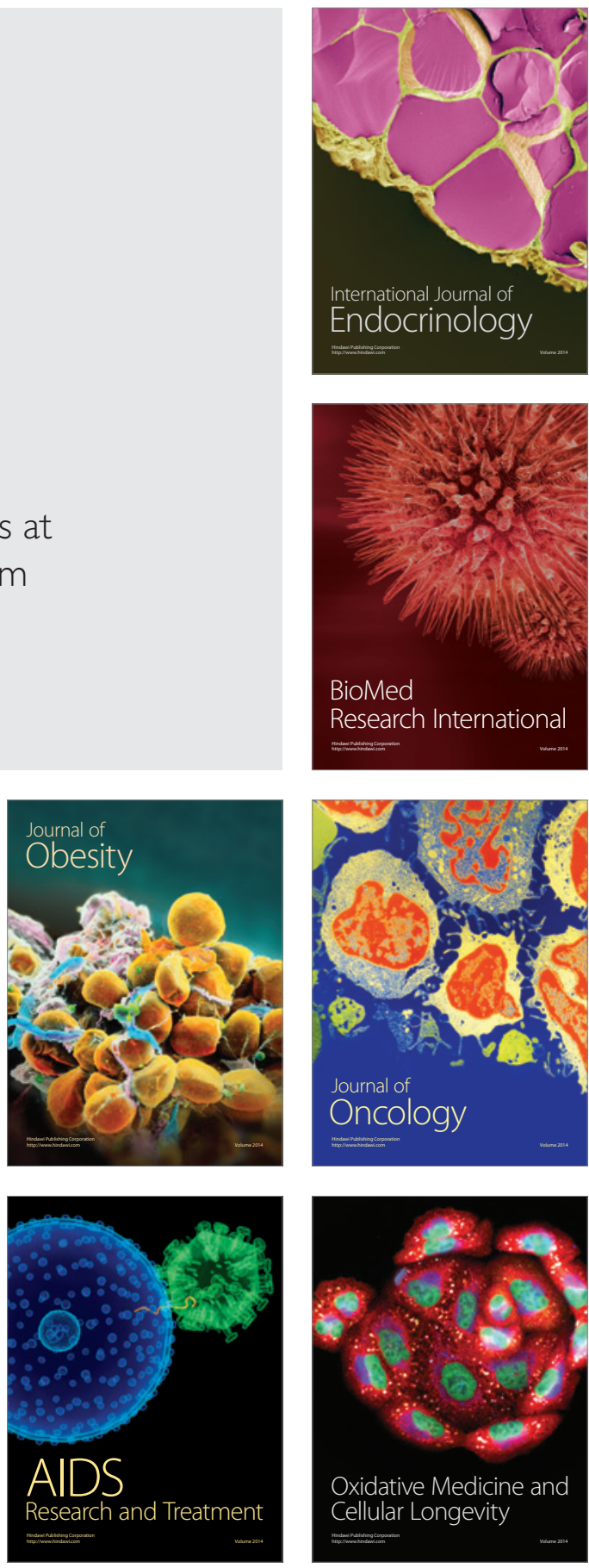